\title{
Cryptocurrencies: an analysis of the phenomenon precedents
}

\author{
Ana Clara Lourenço Fregadolli, Marcio Marcelo Belli.
}

\begin{abstract}
The present work seeks to understand what cryptocurrencies are and what they represent. The study proposes to analyze the evolution of the currency and the traditional monetary system, from the beginning of the barter, with the first civilizations until this new proposal of digital model. The main objective will be to understand what are these "digital coins" and their characteristics, comparing them with the emergence and evolution of the monetary system, which is based on reliability, as well as discussing a possible future for this phenomenon. To this end, it will be used theoretical references that contemplate the theme, so that the currency and monetary system trajectory can be understood, in addition to the digital innovation in question.
\end{abstract}

\section{Key words:}

Barter system, currency, cryptocurrency, reliability.

\section{Introduction}

In a scenario in which there are more Brazilians investing in cryptocurrencies than in the São Paulo Stock Exchange, it is fundamental to understand this phenomenon. Cryptocurrencies are still a mystery and cause divergences in the opinions of economists and investors. This phenomenon arises from the desire for freedom in the transactions, eliminating the figure of the intermediary (financial institutions and State, for instance). However, the cryptocurrencies still go through a definition phase. The aim of this work is to understand what currency is, based on its history, trying to understand the emergence of the cryptocurrencies phenomenon and its relationship with the traditional monetary system, as well as the reasons for its creation. It will also propose a possible future scenario.

\section{Results and Discussion}

For being a recent topic, it is difficult to find a reliable base of references on cryptocurrencies, since there are few articles and scientific papers on the subject. It was used the theoretical basis of books and articles for the history of the coin and its evolution along with some articles already published on the main theme and relevant and reliable websites. Through the readings, it was possible to verify the divergent opinions of renowned economists and investors about cryptocurrencies. From the bibliographic analysis, it is understood that the cryptocurrencies are not seen as a currency indeed, since it is not a financial asset, because most people do not acquire cryptocurrencies to buy goods or engender a store of value. They are seen as an investment and as a way to build wealth quickly and easily. The system of buying and selling cryptocurrencies, especially bitcoin, only occurs and only provides returns because of the supply and demand relationship. However, in order to the incomes to each offer be equal or greater than those of past sale, the value of bitcoin needs to increase. Thus, the value rises exponentially so that returns on investments remain attractive. So, as with the financial bubbles, as long as there is demand, even with those high values, the system goes well. However, when the value reaches a high that does not keep up with the trust, belief and reliability on the part of the interested ones (demand), the bubble will collapse. It can be analyzed that the system of transactions of the cryptocurrencies, as well as the traditional monetary system and the old system of exchanges work through fiduciary and trust deposited on the currency, the system itself or the other party involved. Both systems are based on trust, reliability. However, what cryptocurrencies brings to its users is the freedom so desired by them: non-traceability, anonymity, autonomy and power over their finances without intervention from third parties. This autonomy and freedom retake the primordial idea of the traditional monetary system: the free issuance of bonds and currencies and the barter itself without intermediation. The bitcoin system, blockchain, is a new technology that carries with it the oldest feature that still emerged with the exchange system, the exclusion of the mediator figure in transactions. The divergent opinions on the subject arise through the belief and trust of each one. While some place their trust in financial institutions and the State, others rely on the blockchain system and defend their autonomy and power.

\section{Conclusions}

In general, it may be noted that the power to determine both the use of traditional fiduciary currency in the exchange system and the use of bitcoin in the blockchain system is based on the reliance placed on each format. Cryptocurrencies are not guaranteed by any government or monetary authority, but by the simple trust placed on them. Thus, it can be said that fiduciary and reliability is the determining basis for divergent opinions about cryptocurrencies.

\section{Acknowledgement}

\section{Sponsor Institution: SAE/UNICAMP}

COSTAL, Glauco Zerbini; MEIRA, Liziane Angelotti. Cryptocurrencies: currency, financial asset or a new tulip. Economic Analysis of Law Review, [S. l. ], 2019.

REIS, Tiago. Vale a pena investir em Bitcoin? Veja a opinião de grandes nomes do mercado. [S.l.], 8 Jan. 2018. Available on: https://www.sunoresearch.com.br/artigos/vale-pena-investir-em-bitcoin-vejaopiniao-de-grandes-nomes-do-mercado/. Access on: May 4 $4^{\text {th }}, 2018$.

WEISENTHAL, Joe. ROBERT SHILLER: Bitcoin Is an Amazing Example of a Bubble. [S.l.], 24 Jan. 2014. Available on: https://www.businessinsider.com/robert-shiller-bitcoin-2014-1/. Access on: September $14^{\text {th }}, 2018$. 